\title{
ANALISIS POTENSI REDUKSI SAMPAH DI KECAMATAN BANUHAMPU KABUPATEN AGAM
}

\author{
Putri Nilam Sari ${ }^{1)}$, Fitria Ramadhani ${ }^{2)}$, Nizwardi Azkha ${ }^{3)}$ \\ Departemen K3 dan Kesehatan Lingkungan, Fakultas Kesehatan Masyarakat, Universitas Andalas \\ email: nilam@ph.unand.ac.id
}

\begin{abstract}
Abstrak
Abstrak: Kecamatan Banuhampu tidak memiliki tempat pengelolaan akhir sampah dan sampai sekarang sampah di Kecamatan Banuhampu masih dibuang ke TPA regional Payakumbuh. Sudah saatnya Kecamatan Banuhampu beralih ke paradigma baru pengelolaan sampah yang fokus pada reduksi sampah. Tujuan penelitian ini adalah untuk menganalisis potensi reduksi sampah di Kecamatan Banuhampu, Kabupaten Agam. Jenis penelitian yang dilakukan dalam penelitian ini adalah penelitian deskriptif kualitatif. Penelitian ini dilakukan di Kecamatan Banuhampu dari bulan Februari-Juli 2020. Informasi dikumpulkan dari wawancara mendalam, telaah dokumen, dan observasi. Tujuh informan untuk wawancara mendalam ditentukan dengan teknik purposive sampling. Pengolahan dan analisis data menggunakan triangulasi sumber dan metode. Hasil penelitian menemukan bahwa pada indikator perubahan paradigma belum terdapat kebijakan 3R dan belum terlihat penerapannya. Pada kegiatan 3R belum ditemukan kebijakan dan program khusus. Akan tetapi terdapat beberapa individu atau kelompok tertentu yang melakukan untuk kepentingan pribadi walaupun sosialisasi ke masyarakat sudah sering dilakukan. Pada indikator bank sampah belum terdapat bank sampah dan masih direncanakan. Sedangkan pada indikator waste to energy belum ada kebijakan dan fasilitas yang memadai. Disarankan agar semua pihak bermusyawarah untuk mendapatkan solusi dari kendala yang ada karena sebenarnya banyak sekali peluang pengurangan sampah melalui daur ulang sampah dan pemanfaatan sampah di Kecamatan Banuhampu salah satunya melalui pengomposan.
\end{abstract}

Kata kunci: perubahan paradigma pengelolaan sampah, 3R, bank sampah, waste to energy

Abstract: Banuhampu District does not have a final waste management site, and until now, the waste in Banuhampu District is still being dumped into the Payakumbuh final disposal site. It is time for Banuhampu District to switch to a new paradigm of waste management that focuses on reducing waste. This study aims to analyze the potential for waste reduction in the Banuhampu District, Agam Regency. This type of research conducted in this research is descriptive qualitative research. This research was conducted in Banuhampu District from February to July 2020. Information was collected from in-depth interviews, document review, and observation. Seven informants for in-depth interviews were determined by purposive sampling technique-processing and data analysis using triangulation of sources and methods. The results showed that there is no Triple-R policy on the paradigm change indicator, and no implementation has been seen. In the $3 R$ activities, no specific policies and programs were found. However, some individuals or groups do it for personal gain even though socialization to the community has often been done. In the waste bank indicator, there is no waste bank, and it is still being planned. Meanwhile, in the Waste to Energy indicator, there are no adequate policies and facilities. It is recommended that all parties consult to find solutions to the existing obstacles because there are many opportunities to reduce waste through waste recycling and waste utilization in Banuhampu District, one of which is composting.

Keywords: paradigm shift in waste management, Triple- $R$, waste bank, waste to energy

\section{PENDAHULUAN}

Timbunan sampah berdampak buruk bagi kesehatan dan lingkungan. Untuk itu diperlukan langkah-langkah yang tepat dan strategis dalam menangani permasalahan sampah. Kebiasaan membuang sampah 
sembarangan, menumpuk sampah, membakar sampah, dan mencampur antara sampah organik dan anorganik masih banyak ditemukan di masyarakat. Sampah yang tidak dikelola dengan baik akan memiliki dampak yang sangat besar bagi lingkungan dan kesehatan. Misalnya pemanasan global yang disebabkan oleh gas metan dari timbunan sampah, polusi udara akibat pembakaran sampah, dan berbagai masalah kesehatan seperti diare yang diakibatkan oleh vektor (Hoornweg and Bhada-Tata, 2012).

Kecamatan Banuhampu termasuk salah satu daerah yang memiliki persoalan tentang sampah. Disamping kepadatan penduduk yang tinggi, daerah ini tidak memiliki tempat pemrosesan akhir sampah serta sampah masih dibuang ke sembarang tempat. Topografi wilayah ini beberapa diantaranya memiliki banyak ngarai, dan masyarakat masih membuang sampah sembarangan ke ngarai. Hal ini menimbulkan permasalahan ke daerah tetangga yaitu Kota Bukittinggi karena sampah yang dibuang ke ngarai yang ada di Kecamatan Banuhampu akan sampai melewati aliran sungai di Ngarai Sianok Bukittinggi. Tidak adanya TPA di wilayah ini disebabkan oleh keterbatasan lahan. Kabupaten Agam termasuk daerah dataran tinggi sehingga jika dibangun suatu tempat pemrosesan akhir sampah, ditakutkan akan mencemari sumber air yang otomatis akan menyebabkan dampak buruk bagi kesehatan masyarakat. Oleh sebab itu, sampah-sampah yang ada di Kecamatan Banuhampu biasanya dikumpulkan dan dibuang ke TPA regional Payakumbuh. Namun TPA Payakumbuh juga memiliki daya tampung yang terbatas karena TPA regional Payakumbuh juga menerima sampah dari kabupaten dan kota lainnya untuk pembuangan akhir sampah.

Oleh karena itu diperlukan usaha pengelolaan yang berkesinambungan untuk meminimalisir dampak negatif dari sampah. Paradigma pengelolaan sampah yang dulunya bertumpu pada pengelolaan kumpul - angkut - buang sudah saatnya diganti ke paradigma baru pengelolaan sampah yaitu pengelolaan yang lebih mengutamakan dalam hal pengurangan sampah (Danish et al., 2019). Pengurangan sampah dilakukan dengan daur ulang, pembatasan timbulan sampah, dan pemanfaatan kembali sampah. Pengurangan sampah ini didukung dengan prinsip 3R (Reduce, Reuse, Recycle) dan konsep Waste to Energy. Pada paradigma baru ini sampah lebih mempunyai nilai ekonomis dan manfaat bagi kehidupan manusia (Danish et al., 2019).

Hal ini sesuai dengan Undang-undang No. 18 tahun 2008 tentang pengelolaan sampah. Pada regulasi ini tertulis mengenai pengelolaan sampah harus dilakukan dengan sistematis dan berkelanjutan, dengan mendahulukan kegiatan pengurangan sebelum melakukan penanganan sampah. Kegiatan pengurangan sampah adalah usaha agar jumlah sampah yang diangkut ke TPA dapat berkurang sehingga sampah yang dibuang hanya berupa residu yang tidak dapat lagi dikelola lebih lanjut. Dalam hal pengurangan sampah, beberapa hal yang dilakukan adalah 3R yang terdiri dari reduce, reuse, dan recycle. Reduce adalah pengurangan sampah. Reuse adalah penggunaan kembali sampah yang tidak berguna lagi. Recycle adalah mendaur ulang sampah. Keberhasilan dari prinsip $3 \mathrm{R}$ ini akan tergantung pada kerjasama antara pemerintah dan masyarakat (Sekretariat Negara RI, 2008).

Beberapa daerah yang menerapkan prinsip 3R dalam pengelolaan sampah terkendala dalam mengoptimalkan kegiatan tersebut karena belum adanya TPST (Tempat Pengelolaan Sampah terpadu) dikarenakan keterbatasan lahan, masih kurangnya ketersediaan tenaga kerja, serta kurangnya kesadaran masyarakat (Qodriyatun, 2014; Yuneke, 2016; Widiyanti et al., 2019)

Penelitian ini dilakukan untuk mengetahui potensi pengurangan sampah 
sejak dari sumbernya. Penerapan reduksi sampah ini bermanfaat untuk mengurangi perilaku buang sampah sembarangan dan volume sampah di TPA menjadi berkurang.

\section{METODE PENELITIAN}

Desain penelitian yang dilakukan dalam penelitian ini adalah penelitian Deskriptif Kualitatif. Penelitian ini digunakan untuk menggali informasi secara mendalam dan dengan cakupan yang luas mengenai analisis potensi reduksi sampah di Kecamatan Banuhampu.

Penelitian ini dilakukan di Kecamatan Banuhampu Kabupaten Agam. Penelitian ini dilakukan dari bulan Februari sampai dengan bulan Juli tahun 2020. Teknik penentuan informan dalam penelitian ini adalah secara purposive sampling sehingga didapatkan informan penelitian ini berjumlah 7 orang yang terdiri dari Camat Kecamatan Banuhampu Kabupaten Agam, Kepala Seksi Pemberdayaan Masyarakat dan Nagari Kecamatan Banuhampu, Kepala Puskesmas Padang Lua, Pemegang Program Kesehatan Lingkungan Puskesmas Padang Lua, Wali Nagari Cingkariang Kecamatan Banuhampu, Masyarakat (Sekretaris Kelompok Swadaya Masyarakat dan Pedagang). Data dikumpulkan melalui wawancara mendalam dan observasi. Kemudian dilakukan triangulasi sumber dan metode untuk menjamin validasi data.

\section{HASIL DAN PEMBAHASAN Perubahan Paradigma}

Berdasarkan hasil penelitian, perubahan paradigma di Kecamatan Banuhampu masih belum terlihat karena belum adanya kebijakan dan peraturan dari pemerintah mengenai perubahan paradigma sistem pengelolaan sampah. Perubahan paradigma tersebut adalah mengubah paradigma pengelolaan sampah lama yang bertumpu pada penanganan sampah (kumpul-angkut-buang) menjadi paradigma pengelolaan sampah baru yang lebih fokus pada kegiatan pengurangan sampah. Selain itu kebiasaan dari masyarakat Kecamatan Banuhampu yang sudah terbiasa menggunakan paradigma pengolahan sampah yang lama. Masyarakat masih membuang sampah ke selokan, ngarai, pinggir jalan, serta membakar sampah di sekitar rumah masing-masing tanpa memikirkan dampah terhadap perilaku tersebut.

Kondisi ini perlu diubah dengan meningkatkan pemahaman tentang paradigma baru pengelolaan sampah, bahwa pengurangan sampah mutlak dilakukan yaitu membatasi timbulan sampah, mendaur ulang sampah, dan memanfaatkan kembali sampah. Manfaat akhir dari kegiatan ini adalah agar hanya tersisa residu sampah yang diangkut ke TPA, sehingga mengurangi kebutuhan lahan untuk menimbun sampah.

Paradigma pengelolaan sampah yang diterapkan sekarang ini sebaiknya menggunakan pendekatan dengan penyelesaian di akhir yaitu dengan prinsip 3R (Reduce, Reuse, Recycle) dan pemanfaatan sampah (waste utilisation). Sesuai dengan hirarki pengelolaan sampah, terdapat tahapan strategi pengelolaan sampah yang harus lebih diprioritaskan dibandingkan dengan tahapan lainnya. pengelolaan sampah berdasarkan hirarki pengelolaan sampah yaitu dimulai dari reduce, reuse dan recycle, energy recovery dan disposal (Bartl, 2014).

Pengelolaan sampah lebih dipengaruhi oleh karakter sosial budaya karena kegiatan pengelolaan sampah untuk berpedoman pada paradigma baru berkaitan dengan pola pikir serta perilaku (patterns of behavior) dalam memandang dan memperlakukan sampah. Kapasitas pengetahuan, sikap, dan keterampilan masyarakat perlu disesuaikan dengan kondisi dan karakteristik masyarakat. Pemimpin atau tokoh masyarakat perlu melakukannya dengan tepat supaya dapat mengajak masyarakat dalam berpartisipasi dalam kegiatan pengurangan sampah (Puspitawati and Rahdriawan, 2012) 
Penelitian sebelumnya mengenai pengelolaan sampah terpadu berbasis masyarakat berdasarkan hasil perhitungan dalam analisis multidimensional scaling (MDS), diperoleh jenis pengolahan sampah yang dapat diterapkan adalah daur ulang kertas dan komposting. Kegiatan ini dilakukan dengan meningkatkan kinerja operasional pengelolaan sampah, pengolahan sampah, dan strategi pemberdayaan masyarakat dengan menitik beratkan pada konsep pembangunan yang partisipatif (Yogiesti, Hariyani and Sutikno, 2012).

Untuk menangani masalah sampah agar bernilai ekonomi, hal pertama yang harus dilakukan adalah dengan memilah sampah yang setiap hari diproduksi, yang kedua adalah memakai kembali sampah yang mungkin bisa dipakai kembali dan yang terakhir adalah mendaur ulang sampah agar bisa bernilai ekonomi. Sebelum mendaur ulang tentunya masyarakat harus disiplin dalam memilah sampah. Memilah sampah sangat diperlukan, karena dengan memilah sampah, dapat diketahui sampah mana saja yang bisa digunakan dan yang bisa didaur ulang. Misalnya sampah organik yang bisa dibuat menjadi kompos, sampah kertas bisa didaur ulang menjadi kertas daur ulang, dan sampah yang dapat langsung bisa dijual seperti, kaleng, ember, botol (Gunawan, 2018).

Kecamatan Banuhampu perlu membuat peraturan tegas serta program yang jelas berkaitan dengan pengelolaan sampah yang bertumpu pada pengurangan sampah. Perlu juga kerjasama berbagai pihak dalam merencanakan kebijakan tersebut baik dari pemerintah maupun masyarakat. Merubah kebiasaan dan pola pikir masyarakat akan menjadi tantangan kedepannya. Dengan adanya perubahan paradigma pengelolaan sampah pada masyarakat yang lebih fokus pada pengurangan sampah, sampah dapat dimanfaatkan secara lebih baik. emanfaatkan sampah juga bisa menjadi nilai ekonomi bagi daerah. Beberapa cara menerapkan paradigma baru pengelolaan sampah adalah dengan usaha daur ulang sampah kertas dan plastik, pengelolaan kompos, pemilahan sampah, melalui bank sampah, serta pemanfaatan sampah menjadi energi.

\section{R (Reduce, Reuse, Recycle)}

Berdasarkan penelitian yang sudah dilakukan, usaha 3R (Reduce, Reuse, Recycle) di Kecamatan Banuhampu masih belum berjalan dengan baik. Tidak ada peraturan dan program khusus yang berkaitan dengan 3R di Kecamatan Banuhampu. Tetapi sosialisasi 3R kepada masyarakat masih tetap dilakukan dari berbagai pihak seperti dari kecamatan, puskesmas, dan nagari. Adapun beberapa fasilitas untuk menunjang 3R seperti tempat pengomposan dan daur ulang sampah di Nagari Cingkariang dan alatalat untuk pengomposan di daerah Taluak. Walaupun fasilitas tersebut masih cukup dan kondisinya masih memadai, tetapi fasilitas tersebut sekarang sudah tidak dipergunakan lagi atau sudah tidak dijalankan lagi karena beberapa kendala. Kendala dalam menjalankan upaya 3R tersebut berupa belum adanya peraturan yang jelas, biaya, sumber daya manusia, dan kesadaran masyarakat.

Reduce merupakan usaha untuk meminimalkan barang atau material yang digunakan, menurunkan hasil buangan. Kegiatan yang termasuk kedalam reduce seperti melakukan isi ulang air minum, menggunakan tinta yang dapat diisi ulang, dan lainnya. Selain itu menggunakan bungkus makanan yang mudah terdegradasi seperti daun (untuk menghindari pemakaian plastik), mengurangi penggunaan kemasan yang berlebihan, kurangi penggunaan bahan sekali pakai, hindari membeli dan memakai barang-barang yang kurang perlu, dan gunakan saputangan daripada menggunakan tisu (KemenPU, 2010). 
Reuse merupakan usaha pengurangan sampah dengan memilih barang-barang yang dapat digunakan kembali. Pemanfaatan limbah dengan jalan menggunakannya kembali untuk keperluan yang sama atau fungsi yang sama tanpa melalui pengolahan atau pun mengubah bentuk. Masyarakat sebaiknya menghindari pemakaian barang-barang yang sekali pakai langsung dibuang. Kegiatan reuse seperti botol bekas digunakan kembali untuk fungsi yang sama atau lainnya, ember bekas digunakan menjadi pot untuk bunga, kantong asoy dapat digunakan kembali, botol plastik atau gelas dapat dijadikan tempat bumbu, koran atau kertas menjadi pembungkus, kaleng susu dapat digunakan untuk celengan (Arisona, 2018)

Recycle yaitu mendaur ulang barangbarang yang sudah tidak digunakan lagi. Upaya pemanfaatan limbah melalui pengolahan fisik atau kimiawi sehingga menghasilkan produk yang sama seperti barang semula atau dalam bentuk dan fungsi yang lain. Kegiatannya seperti bekas botol minum dalam kemasan bisa didaur ulang menjadi tempat pensil, sampah organik diolah menjadi kompos, pecahan-pecahan beling diolah lagi menjadi gelas, potongan plastik diolah menjadi ember, lempengan kaleng diolah kembali menjadi kaleng (KemenPU, 2010)

Pada usaha reduce, beberapa orang sudah menggunakan teknik isi ulang air minum dengan menggunakan galon. Mengurangi sampah plastik dan kemasan masih belum dilakukan. Pada usaha reuse, ada beberapa masyarakat yang menggunakan kembali plastik bekas, ember bekas, dan botol bekas untuk dijadikan pot. Koran atau kertas menjadi pembungkus juga ada tapi tetap diberi kantong plastik setelah membungkusnya.

Pada usaha recycle, terdapat kelompok masyarakat di Nagari Pakan Sinayan yang melakukan daur ulang kemasan plastik untuk dijadikan kerajinan. Namun usaha tersebut tidak dilakukan secara rutin dan terus menerus. Jadi berdasarkan penelitian yang telah dilakukan, penerapan $3 \mathrm{R}$ di Kecamatan Banuhampu masih jauh dari yang seharusnya. Hanya sebagian kecil masyarakat yang mamanfaatkan kembali sampah dan itupun hanya keinginan individu saja.

Untuk menerapkan pengurangan sampah berbasis $3 \mathrm{R}$, proses pengurangan sampah dimulai dari pemilahan sampah. Sampah dipilah antara sampah organik, anorganik, serta sampah berbahaya. Dari sampah organik, bisa diolah menjadi kompos. Sampah anorganik seperti kertas dan plastik dapat didaur ulang kembali. Sementara sampah yang tidak bisa diolah lagi, dibuang ke tempat pemrosesan akhir sampah. dengan begitu masyarakat dapat mengurangi sampah yang akhirnya akan dibuang ke TPA (KemenPU, 2010).

Pada dasarnya, sistem daur ulang dapat diaplikasikan dengan pengomposan karena komposisi sampah terbanyak adalah organik. Masyarakat perlu disosialisasikan mengenai pengomposan untuk skala individual, komunal, kawasan. Sedangkan, sampah organik dan anorganik juga dapat dikelola melalui sistim bank sampah. Dalam pengurangan sampah, perlu dijelaskan cara-cara sederhana yang dapat diaplikasikan dalam kehidupan sehari-hari, seperti mengurangi penggunaan kemasan plastik dan lebih memilih untuk menggunakan kemasan yang mudah terdegradasi. (KemenPU, 2010).

Kesuksesan kegiatan 3R memerlukan partisipasi aktif seluruh stakeholder untuk melakukan upaya penyadaran pentingnya mengurangi jumlah sampah, mulai dari sumbernya. Peningkatan pemahaman masyarakat dapat dilakukan melalui promosi dan sosialisasi yang terus menerus dan berkelanjutan terhadap setiap strata masyarakat, individu maupun kelompok. Kegiatan ini dilakukan dengan menggunakan bahasa yang sesuai dengan kelompok masyaratak yang dituju dengan menggunakan media yang menarik (KemenPU, 2010).

Hal ini sejalan dengan penelitian sebelumnya bahwa penerapan prinsip 3R 
dalam kegiatan pengelolaan sampah belum dapat dilaksanakan secara optimal dikarenakan beberapa hambatan seperti belum adanya TPST dikarenakan keterbatasan lahan, masih kurangnya ketersediaan tenaga kerja, dan kurangnya kesadaran masyarakat (Yuneke, 2016).

Kecamatan Banuhampu memerlukan peraturan dan program yang jelas untuk usaha pengelolaan sampah melalui 3R. Berdasarkan hasil penelitian, Kecamatan Banuhampu termasuk daerah sentral penghasil sayur. Oleh karena itu, besar peluang bagi Kecamatan Banuhampu untuk mengurangi jumlah sampah organik melalui usaha $3 \mathrm{R}$ terutama dengan cara pengomposan. Sebaiknya peluang ini bisa dimanfaatkan dengan baik.

Dengan adanya peraturan yang dibuat, anggaran dan SDM yang diperlukan untuk usaha 3R juga akan jelas. Jika dana telah tersedia, fasilitas-fasilitas yang ada seperti tempat pengomposan juga akan berjalan dan dimanfaatkan kembali Pemerintah dan masyarkaat dapat bermusyawarah untuk melaksanakan 3R agar masyarakat dapat meningkatkan kesadaran mengenai pengurangan sampah sejak dari sumbernya sehingga mudah untuk melaksanakan 3R.

\section{Bank Sampah}

Berdasarkan penelitian yang sudah dilakukan, belum ada kebijakan terkait dengan bank sampah. Fasilitas bank sampah telah disediakan oleh pemerintah di Nagari Cingkariang. Namun sejak awal didirikan belum berjalan karena keterbatasan biaya. Perencanaan bank sampah di Nagari Taluak juga belum berjalan dan sedang dilakukan proses studi banding ke daerah lain seperti Bukittinggi yang sudah memiliki bank sampah.

Sampah yang dikumpulkan dapat ditukar menjadi uang yang ditabung ke dalam rekening masing-masing. Masyarakat dapat mengambil uang tersebut sewaktu-waktu apabila uang dalam rekening tersebut sudah terkumpul banyak. Sampah yang disetorkan ke bank sampah dapat dibedakan menjadi beberapa jenis, misalnya sampah organik seperti sayuran dan sisa makanan maupun sampah anorganik seperti plastik, besi, dan lainnya. Terdapat harga beli masing-masing jenis sampah yang telah ditetapkan oleh bank sampah (Selomo et al., 2017).

Bank sampah di Nagari Taluak hanya sebatas mengelola sampah organik lalu kemudian sampahnya diolah menjadi kompos. Kedepannya pemerintah daerah setempat berencana akan menjadikan bank sampah resmi seperti daerah lain yang juga mengolah sampah plastik, kaleng, botol, dan lainnya serta peserta memiliki rekening pada bank sampah tersebut.

Jika berjalan dengan efektif, program pengelolaan sampah mandiri melalui Bank Sampah dapat menjadi solusi yang efektif bagi pemerintah dan masyarakat. Hal ini sebagai solusi untuk mengurangi peningkatan volume sampah yang semakin tidak terkendali. Selain memberikan dampak positif terhadap lingkungan, dalam proses pengelolaannya, bank sampah memiliki mekanisme relasi dan jaringan sosial yang bernilai ekonomis (Suryani, 2014).

Penelitian sebelumnya menunjukkan bahwa pengaruh keberadaan bank sampah terhadap reduksi produk sampah cukup efektif dan tepat. Pengaruh Bank Sampah terhadap perilaku masyarakat dapat menekan produksi harian sampah, masyarakat yang dulunya memilih untuk mengelola sampah dengan membakar sampah atau membuang ke TPA lebih untuk menabungkan sampahnya, masyarakat lebih rajin untuk memilah sampah rumah tangga domestik karena terbiasa dengan jadwal rutin transaksi sampah, pengurangan penyakit seperti DBD dan diare dan masyarakat lebih memahami sampah yang harus dikelola ataupun yang tidak bisa dikelola (Rahman and Anna, 2017).

Kecamatan Banuhampu saat ini sebaiknya mulai gencar dalam mendirikan dan menjalankan bank sampah. diperlukan 
program dan anggaran yang jelas untuk bank sampah. Bank sampah adalah metode yang efektif dalam menangani permasalahan sampah yang ada di Kecamatan Banuhampu. Program ini dapat mengurangi sampah yang biasa dibuang ke TPA, sampah dapat dikelola dengan baik, sampah harian masyarakat bisa ditekan, masyarakat akan lebih rajin memilah sampah karena adanya jadwal rutin dari bank sampah, dan dapat mengurangi penyakit akibat sampah. Fokus dan bersungguh-sungguh terhadap rencana pendirian bank sampah adalah cara agar kegiatan ini dapat diterapkan dan agar bisa berjalan dengan baik.

\section{Waste to Energy}

Berdasarkan penelitian yang telah dilakukan, diketahui bahwa tidak terdapat kebijakan mengenai Waste to Energy di Kecamatan Banuhampu. Kebijakan untuk hal tersebut masih belum pernah dibahas sama sekali oleh pemangku kepentingan. Sarana dan prasarana untuk Waste to Energy juga belum ada. Sebelumnya pernah terdapat rencana untuk membangun tempat mengelola sampah menjadi energi serta segala usaha untuk memanfaatkan sampah. Selain itu akan dibangun tempat pengelolaan sampah dalam sakala besar. Akan tetapi hal tersebut mengalami penolakan dari masyarakan, sehingga memerlukan semua butuh lahan yang luas dan jauh dari pemukiman.

Penyediaan sumber energi baru dan terbarukan dapat dilakukan oleh sebuah badan usaha yang difasilitasi pemerintah daerah dengan memikirkan nilai ekonomis yang dicapai dalam jangka waktu tertentu. Penerapannya difasilitasi dengan sistem pengumpul dan konversi energi dari gas metana yang terbentuk selama sampah ditimbun. Proses alamiah anaerobik akan berlangsung dalam timbunan sampah organik akan menghasilkan gas metana. Energi terbarukan yang dihasilkan diharapkan dapat memberikan kontribusi sebesar 23\% dari pasokan energi pada tahun 2025 atau hampir setengah dari total kebutuhan energi Indonesia (Sekretariat Negara RI, 2007; Brunner and Rechberger, 2015).

Penelitian sebelumnya mengenai pemanfaatan sampah menjadi listrik di TPA Cilowong Kota Serang Banten didapati bahwa secara teknis di TPA Cilowong Kota Serang terdapat potensi untuk melakukan pengelolaan sampah dengan memanfaatkan energi potensial yang ada di lokasi tersebut. Dari hasil pengamatan lapangan dan hasil penelitian laboratorium didapatkan fakta bahwa sampah yang masuk ke TPA Cilowong memiliki potensi untuk dimanfaatkan sebagai energi listrik, hal ini dibuktikan dengan adanya beberapa parameter teknis pemulihan energi yang memenuhi kriteria, baik melalui teknologi thermokimia (termal) maupun biokimia. Jumlah sampah yang masuk ke TPA Cilowong Kota Serang sebanyak 120 ton setiap harinya secara teoritis dapat menghasilkan listrik sebesar 2,19 MW bila dilakukan dengan teknologi konversi thermokimia, dan 1,09 MW melalui teknologi konversi biokimia (anaerobic digester) (Faridha, Pirngadie and Supriatna, 2015).

Selanjutnya penelitian yang dilakukan di Sunter Jakarta Utara, penerapan teknologi PLT Biomassa diperkirakan dapat berkontribusi besar dalam menyelesaikan permasalahan sampah kota DKI Jakarta, antara lain dapat mengurangi ketergantungan terhadap TPA Bantargebang yang semakin lama daya tampung dan daya dukungnya berkurang. Listrik yang diperoleh dari kegiatan ini merupakan salah satu kegiatan dalam mensukseskan program pengembangan energi baru dan terbarukan dalam mendukung pembangunan berkelanjutan.

Konsep Waste to Energy merupakan kegiatan yang dapat menjadi salah satu solusi dari permasalah sampah Kecamatan Banuhampu. Energi yang dihasilkan merupakan sumber energi yang murah dibandingkan dengan sistem pembangkit listrik lainnya karna memperoleh bahan bakunya sangatlah mudah. Kegiatan ini 
dapat meminimalisasi timbulan sampah yang dapat mencemari lingkungan, sumbernya selalu ada karena cadangan yang sangat besar. Apalagi melihat banyaknya sampah organik di Kecamatan Banuhampu. Akan tetapi usaha Waste to Energy di Kecamatan Banuhampu tidak bisa dijalankan karena adanya keterbatasan lahan dan juga belum ada TPST di Kecamatan Banuhampu. Perlu rencana yang matang untuk pembangunan fasilitas Waste to Energy tersebut dalam skala besar.

\section{KESIMPULAN}

Potensi reduksi sampah di Kecamatan Banuhampu masih belum maksimal dari aspek perubahan paradigma masyarakat dalam pengelolaan sampah, usaha 3R, bank sampah, serta Waste to Energy. Belum terlihat adanya usaha pengurangan sampah sejak dari sumbernya padahal ada beberapa fasilitas yang bisa dimanfaatkan.

Disarankan agar semua pihak bermusyawarah untuk mendapatkan solusi dari kendala yang ada dalam kegiatan 3R. Sebenarnya banyak sekali peluang pengurangan sampah melalui daur ulang sampah salah satunya melalui pengomposan. Untuk nagari, disarankan segera mengajukan peraturan nagari supaya kendala yang ada seperti biaya dan SDM dapat segera diselesaikan dan fasilitas pengomposan bisa berjalan kembali.

\section{DAFTAR PUSTAKA}

Arisona, R. D. (2018). Pengelolaan Sampah 3R (Reduce, Reuse, Recycle) pada Pembelajaran IPS Untuk Menumbuhkan Karakter Peduli Lingkungan. Al Ulya: Jurnal Pendidikan Islam, 3(1), 39-51.

Bartl, A. (2014). Ways and entanglements of the waste hierarchy. Waste Management, 34(1), 1-2.

Brunner, P. H., \& Rechberger, H. (2015).
Waste to energy-key element for sustainable waste management. Waste Management, 37, 3-12.

Danish, M. S. S., Zaheb, H., Sabory, N. R., Karimy, H., Faiq, A. B., Fedayi, H., \& Senjyu, T. (2019). The Road Ahead for Municipal Solid Waste Management in the 21st Century: A Novel-standardized Simulated Paradigm. IOP Conference Series: Earth and Environmental Science, 291(1), 12009.

Faridha, F., Pirngadie, B., \& Supriatna, N. K. (2015). Potensi pemanfaatan sampah menjadi listrik di TPA Cilowang Kota Srang Provinsi Banten. Ketenagalistrikan Dan Energi Terbarukan, 14(2), 103-116.

Gunawan, R. (2018). Peningkatan ekonomi masyarakat dengan memanfaatkan sampah rumah tangga melalui kelompok sadar sampah" Sri Kandi" di Desa Karangtengah, Kecamatan Kemangkon, Kabupaten Purbalingga, Jawa Tengah. UIN Sunan Ampel Surabaya.

Hoornweg, D., \& Bhada-Tata, P. (2012). What a waste: a global review of solid waste management.

KemenPU. (2010). Modul Pengolahan Sampah Berbasis 3 R. In Kementerian Pekerjaan Umum.

Puspitawati, Y., \& Rahdriawan, M. (2012). Kajian pengelolaan sampah berbasis masyarakat dengan konsep 3R (reduce, reuse, recycle) di Kelurahan Larangan Kota Cirebon. Jurnal Pembangunan Wilayah \& Kota, 8(4), 349-359.

Qodriyatun, S. N. (2014). Meningkatkan kesejahteraan masyarakat melalui pengelolaan sampah berdasarkan UU 
No. 18 Tahun 2008. Aspirasi: Jurnal Masalah-Masalah Sosial, 5(1), 2133.

Rahman, R. P., \& Anna, A. N. (2017). Pengaruh Keberadaan Bank Sampah Terhadap Reduksi Produk Sampah Di Kota Surakarta. Universitas Muhammadiyah Surakarta.

Undang-Undang Republik Indonesia No. 30 Tahun 2007 Tentang Energi, Jakarta (2007).

Undang-Undang Nomor 18 tahun 2008 tentang Pengelolaan Sampah, Jakarta: Sekretariat Negara (2008).

Selomo, M., Birawida, A. B., Mallongi, A., \& Muammar, M. (2017). Bank Sampah Sebagai Salah Satu Solusi Penanganan Sampah Di Kota Makassar. Media Kesehatan Masyarakat Indonesia, 12(4), 232240.

Suryani, A. S. (2014). Peran bank sampah dalam efektivitas pengelolaan sampah (studi kasus bank sampah Malang). Aspirasi: Jurnal Masalah-Masalah Sosial, 5(1), 71-84.

Widiyanti, A., Rahmayanti, A., Hamidah, L. N., Chikmawati, Z., Prayogi, Y. R., \& A'yuni, Q. (2019). Pengelolaan Sampah dengan Sistem 3R di Bank Sampah Cangkringsari Berseri Desa Cangkringsari Kecamatan Sukodono Kabupaten Sidoarjo. E-Prosiding SNasTekS, 1(1), 77-82.

Yogiesti, V., Hariyani, S., \& Sutikno, F. R. (2012). Pengelolaan sampah terpadu berbasis masyarakat Kota Kediri. Jurnal Tata Kota Dan Daerah, 2(2), 95-102.

Yuneke, V. (2016). Penerapan Prinsip 3R (Reduce, Reuse, Recycle) dalam Pengelolaan sampah Sebagai Upaya
Pengendalian Pencemaran Lingkungan di Kabupaten Bantul. In Universitas Atma Jaya Yogyakarta. 